\title{
Analysis of peculiar volcanic earthquakes at Satsuma-Iojima volcano
}

\author{
Naokuni Uchida ${ }^{1}$ and Takayuki Sakai ${ }^{2 *}$ \\ ${ }^{1}$ Fukuoka District Meteorological Observatory, J.M.A., Fukuoka 810-0052, Japan \\ ${ }^{2}$ Kagoshima Local Meteorological Observatory, J.M.A., Kagoshima 890-0068, Japan
}

(Received March 30, 2000; Revised February 28, 2001; Accepted November 9, 2001)

\begin{abstract}
Fukuoka District Meteorological Observatory has continued seismic observations at Satsuma-Iojima volcano since September 1997. Of the daily number of seismic events at the volcano, which sometimes exceeded 100 , several different types have been observed. Hypocenters of A-type earthquakes mostly existed in a shallow area within the volcanic island. Numerous peculiar earthquakes that have waveforms different from usual volcanic earthquakes were observed with the ascent of seismic activity. They have an emergent phase that precedes the appearance of the high-amplitude main phase by 5-8 seconds and consists of weak seismic waves increasing gradually in amplitude. This type of earthquakes is considered to be excited by a bubbling of gas and a succeeding shear fracture within the highly viscous rhyolitic magma.
\end{abstract}

\section{Introduction}

Satsuma-Iojima (which means "Sulfur Island in Satsuma (=Kagoshima)" in Japanese) is a volcanic island of $6 \mathrm{~km}$ $(\mathrm{E}-\mathrm{W}) \times 3 \mathrm{~km}(\mathrm{~N}-\mathrm{S})$ wide, which is located $40 \mathrm{~km} \mathrm{SW}$ off the Osumi Peninsula at the south end of Kyushu Island, Japan. This volcanic island is also situated at the NW edge of Kikai caldera which was formed about 6300 years ago, and consists of a part of the outer rim of Kikai caldera and two small strato-volcanoes, i.e., Io-dake and Inamura-dake (e.g., Kobayashi, 1989). Among them, Io-dake is located in the eastern part of the island and is a conical strato-volcano made up of rhyolite. Its baseline diameter is about $2 \mathrm{~km}$, its height is $704 \mathrm{~m}$, and it has a summit crater with a diameter of about $400 \mathrm{~m}$ and a depth of about $150 \mathrm{~m}$. This volcano shows extremely lively fumarolic activity, so there are many fumarolic vents and geothermal fields in the summit area.

The last volcanic activity around Satsuma-Iojima was the 1934-1935 submarine eruption. This eruption occurred at $2 \mathrm{~km}$ E off the island and finally formed a new island called Showa-Iojima (e.g., Japan Meteorological Agency, 1991). A large eruption has not occurred since then, but Io-dake ejected a weak volcanic plume four times on January 18, 1988 and a slight fall of whitish volcanic ash was reported by the Mishima Village Office to Kagoshima Local Meteorological Observatory of Japan Meteorological Agency (KLMO). Subsequently, new fissures emitting volcanic gas were found at the southern part of the summit crater rim in October 1996 (Geological Survey of Japan, 1997).

Fukuoka District Meteorological Observatory of Japan Meteorological Agency (FDMO) began an observation at

*Present affiliation: Meteorological Research Institute, J.M.A., Tsukuba 305-0052, Japan.

Copy right (C) The Society of Geomagnetism and Earth, Planetary and Space Sciences (SGEPSS); The Seismological Society of Japan; The Volcanological Society of Japan; The Geodetic Society of Japan; The Japanese Society for Planetary Sciences.
Satsuma-Iojima volcano on August 28, 1997 in order to understand the usual state of this volcano.

We conducted observations at Satsuma-Iojima volcano twice, July-August 1985 and February-March 1993 (Fukuoka District Meteorological Observatory, 1986, 1993), so this is our third observation of this volcano. In the previous two observations, we observed several small volcanic A-type earthquakes per day. The $S$ - $P$ times of those A-type earthquakes were shorter than 1 second and their hypocenters were considered to exist within the volcanic island. Moreover, we observed volcanic B-type earthquakes, and C-type tremors like that of Sakurajima volcano which sits at the southern part of Kyushu Island (Nagamune, 1975; Kamo et al., 1977).

In the present observation, we conducted seismic observations at this volcano for nearly four years. During the observation period, the volcanic activity of the volcano just ascended. Numerous peculiar earthquakes, which have a characteristic preceding phase called the "Emergent phase" (Ohminato and Ereditato, 1997) and have waveforms apparently different from the above-mentioned A-C types, were observed, and moreover, weak emissions of volcanic ash from the summit crater were also observed frequently.

In this paper, we indicate the results of the present seismic observation at Satsuma-Iojima volcano, and analyze the waveforms of the peculiar earthquakes and propose a model for their source mechanism.

\section{Seismic Observation}

\subsection{Location of seismographs and period of observa- tion}

FDMO accomplished a seismic network at SatsumaIojima volcano on September 10, 1997 and began a seismic observation. Figure 1 shows the seismic network located at the volcanic island. We installed four seismographs (SIO1$\mathrm{SIO} 4)$ in the west area of Io-dake $(0.7-3.3 \mathrm{~km}$ from the sum- 


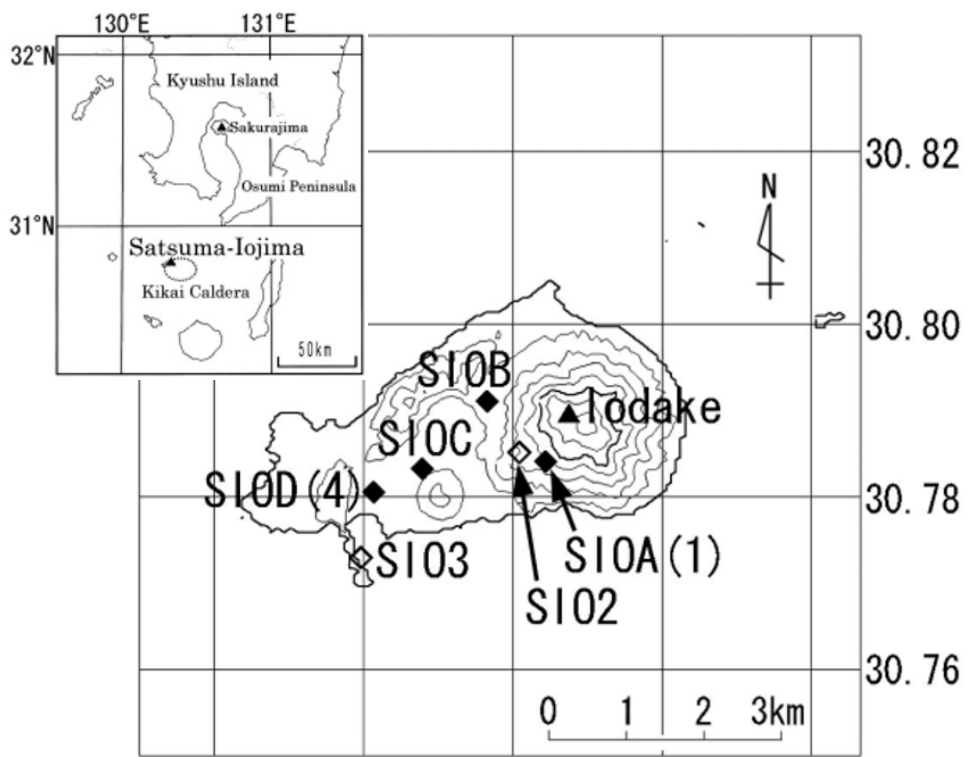

$\begin{array}{lllll}130.26 & 130.28 & 130.30 & 130.32 & 130.34\end{array}$

(1) Sep. 10, 1997-Jan. 25, 1998 (SI01-4)

(2) Jan. 26, 1998-May 20,1998 (SI01)

(3) May 21, 1998-Feb. 27, 1999 (SIOA-D)

(4) Feb. 28, 1999-Continuing (SIOA)

Fig. 1. Seismic network located at Satsuma-Iojima $(\bullet, \diamond:$ Seismic stations).

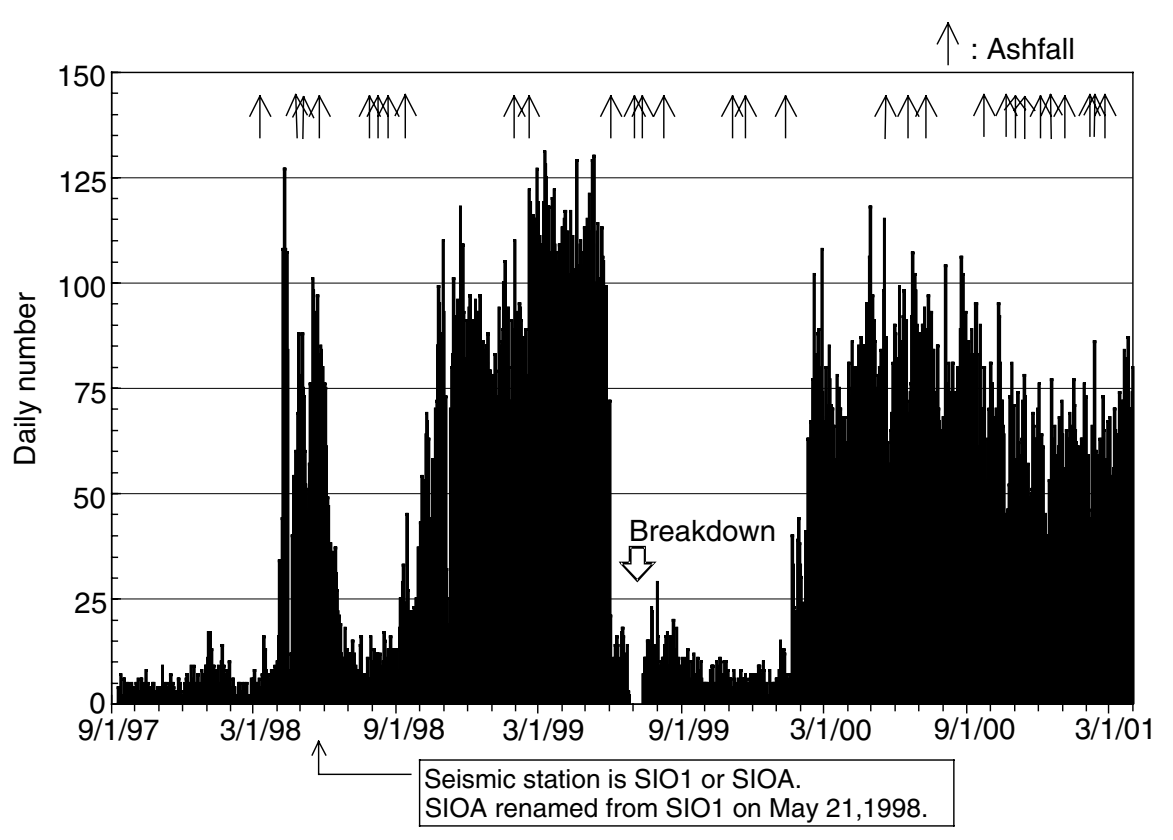

Fig. 2. The daily number of seismic events and the ashfall situation (Sep. 10, 1997-Mar. 31, 2001; Seismic station is SIO1 or SIOA).

mit crater). After a four-month observation, we withdrew three seismographs (SIO2-SIO4) and continued the observation only at SIO1 $(0.7 \mathrm{~km}$ from the summit crater), because seismic activity of the volcano was quiet at that period. In April 1998, the number of seismic events increased, and weak ashfall was also reported by Mishima Village Office Iojima Branch to KLMO. We re-installed three more seismographs in the west area of Io-dake (1.0-3.3 km from the summit crater) on May 21, 1998, and renamed these four observation stations SIOA-SIOD (SIOA is the same point as SIO1, and SIOD is the same point as SIO4). After a ninemonth observation, we again withdrew three seismographs (SIOB-SIOD), and have continued seismic observation at SIOA, which is the nearest station to Io-dake. The speci- 

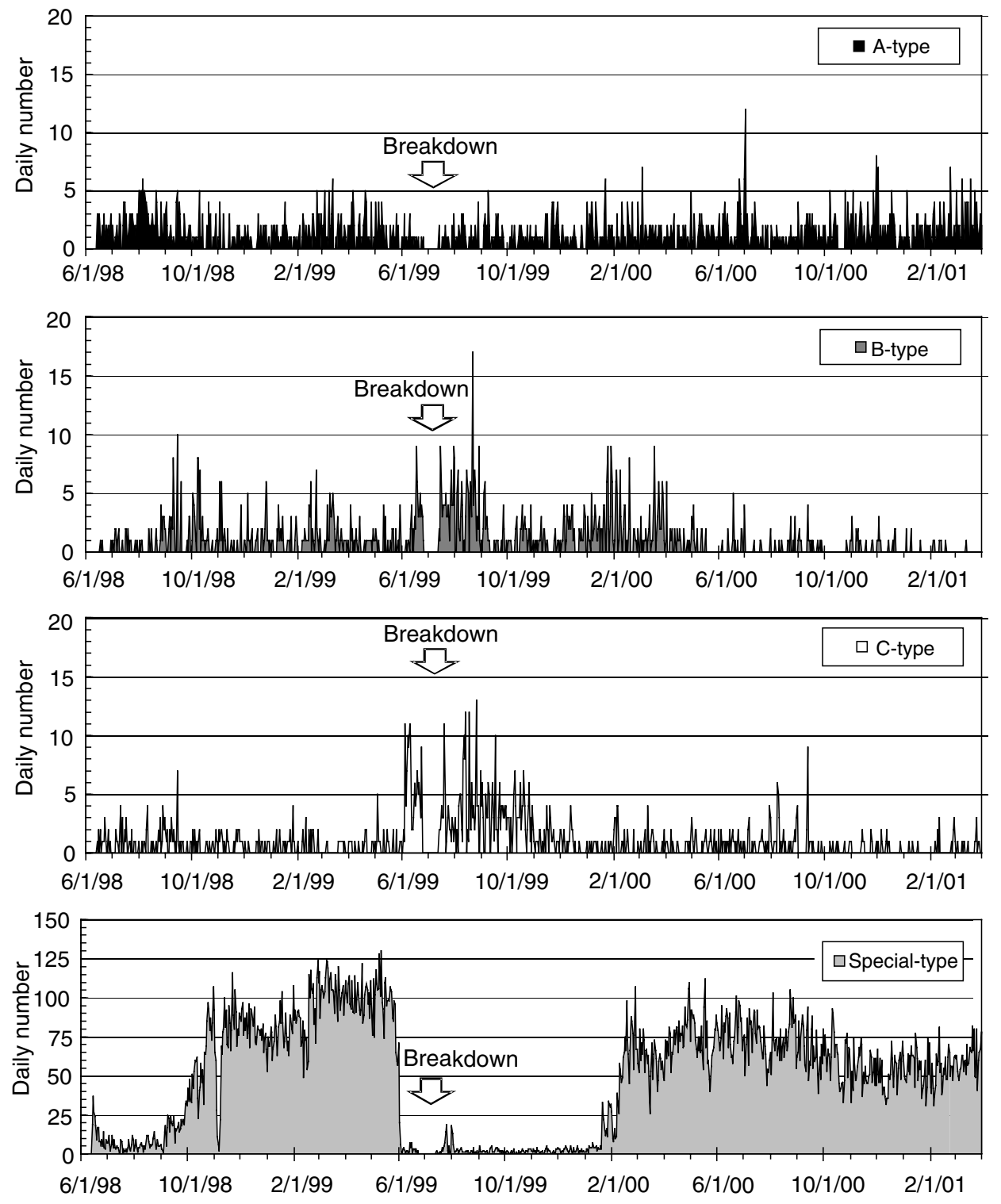

Fig. 3. The daily number of each type of seismic event (Jun. 14, 1998-Mar. 31, 2001; Seismic station is SIOA).

fication of these velocity-type seismographs is as follows: sensitivity $=0.8 \mathrm{~V} \cdot \mathrm{s} / \mathrm{cm}$, proper period $=1.0$ second, and damping constant $=0.5$. The signals of these seismographs are first of all transmitted to Mishima Elementary and Junior High School (SIOD = SIO4) by radio, and then transmitted to FDMO by an exclusive NTT line (a representative telephone company in Japan) in real time. This telemeter system enables us to analyze seismic data immediately at FDMO.

We also installed an infrasonic microphone at Mishima Elementary and Junior High School in the same period that we installed the four seismographs. The main purpose of installation was to detect air-shocks accompanying explosive eruptions. Its sensitivity was $126.4 \mathrm{~Pa} / \mathrm{V}$.

\subsection{Seismic activity}

Figure 2 shows the daily number of seismic events at Satsuma-Iojima volcano. Events with a maximum amplitude lager than $7.5 \mu \mathrm{m} / \mathrm{s}$ in vertical component at station SIOA $(0.7 \mathrm{~km}$ SW from the summit crater, renamed from SIO1 on May 21, 1998) are included in the number. Figure 2 also shows the ashfall situation collected from the reports by Mishima Village Office Iojima Branch, Iojima Police Box of Kagoshima Central Police Station, Geological Survey of Japan, and Sakurajima Volcano Research Center of Disaster Prevention Research Institute of Kyoto University.

The daily number of seismic events ranged from several to ten from September 1997 to March 1998, but increased in April 1998 and amounted to about 30-100 until the middle of June 1998. It decreased once in June 1998, but increased again in September 1998 and amounted to 70-130 until the beginning of June 1999. After this period, it suddenly decreased and ranged from several to twenty, but it increased for the third time from January 21, 2000 and has remained at a high level until now (July 2001). An obvious relation between the increase in the seismic activity and the ashfall has not yet been identified.

Several types of seismic events have been observed at this volcano. We classified them into four types, i.e., Atype earthquake, B-type earthquake, C-type tremor, and an 


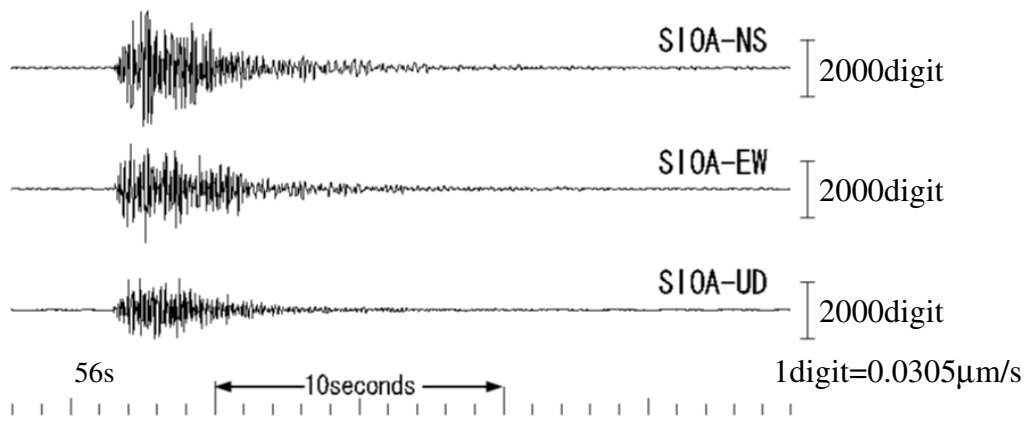

(a) A-type earthquake at 10:24:56 on May 22,1998.

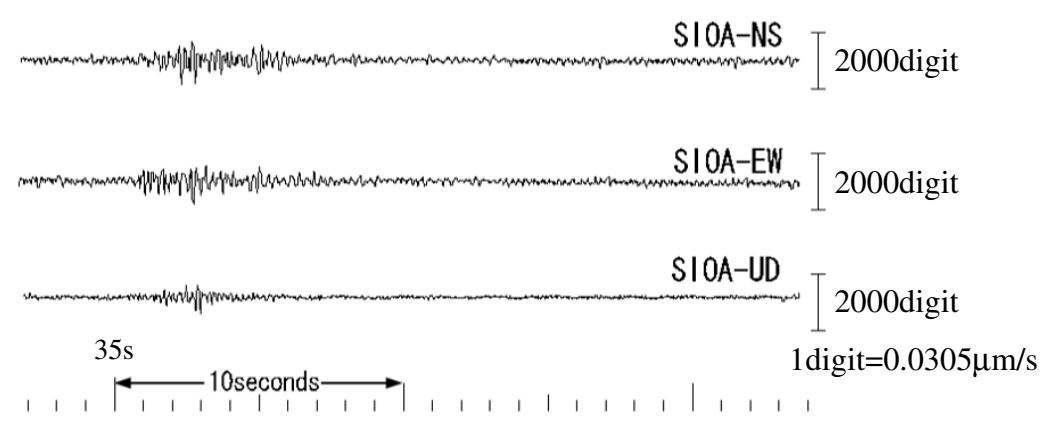

(b) B-type earthquake at 11:03:35 on Nov.27,1998.

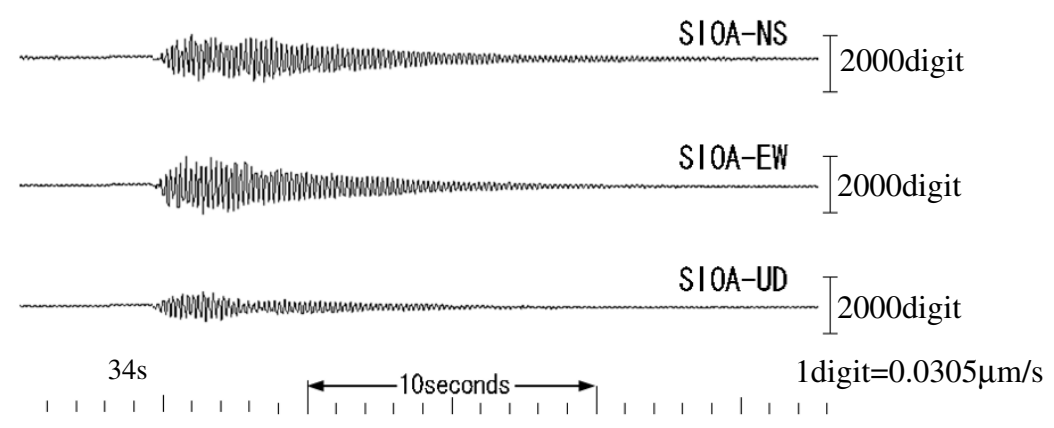

(c) C-type tremor at 05:56:34 on Feb.10,1999.

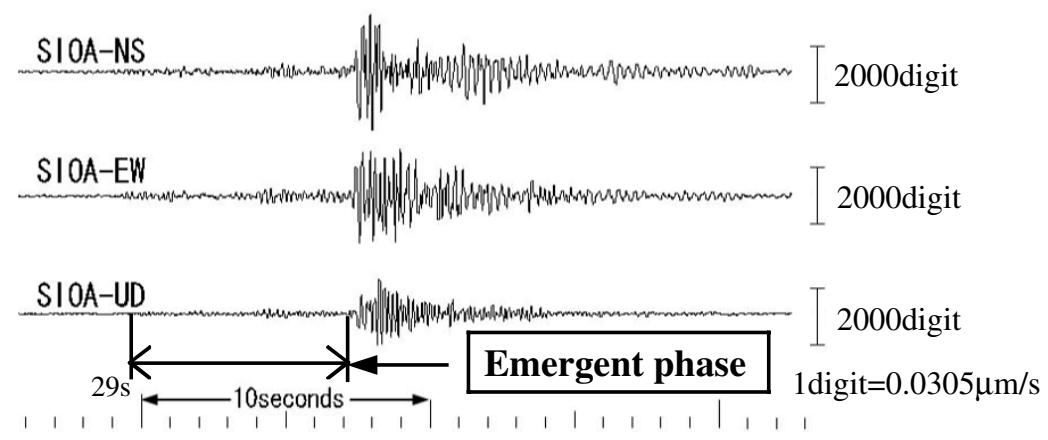

(d) Special-type earthquake at 15:46:29 on May 22,1998.

Fig. 4. Examples of typical waveforms of the four types of seismic events (Seismic station is SIOA).

earthquake which has a long "Emergent phase" (Ohminato and Ereditato, 1997) from June 14, 1998. We call this fourth peculiar type of earthquake a "Special-type earthquake" in this paper.

Figure 3 shows the daily number of four types of seismic events since June 14, 1998 when we started classifying them. The numbers of A-type earthquakes, B-type earthquakes and C-type tremors ranged from several to ten, while that of Special-type earthquakes remained at a high level in the periods of September 1998-May 1999 and January 2000-April 2001. Special-type earthquakes accounted for a large part of the number of all seismic events in the case 

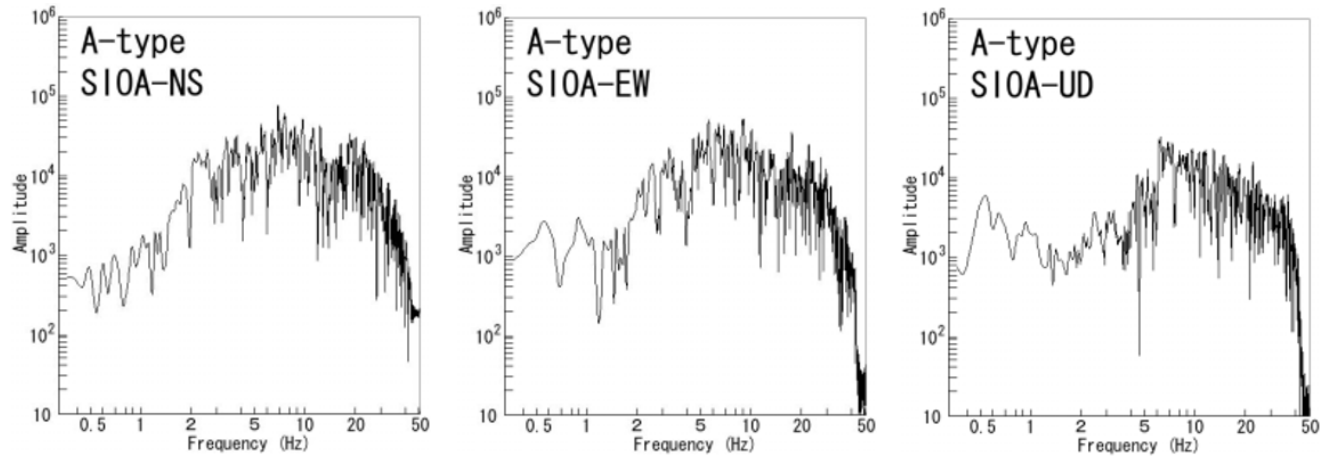

(a) A-type earthquake at 10:24:56 on May 22,1998.
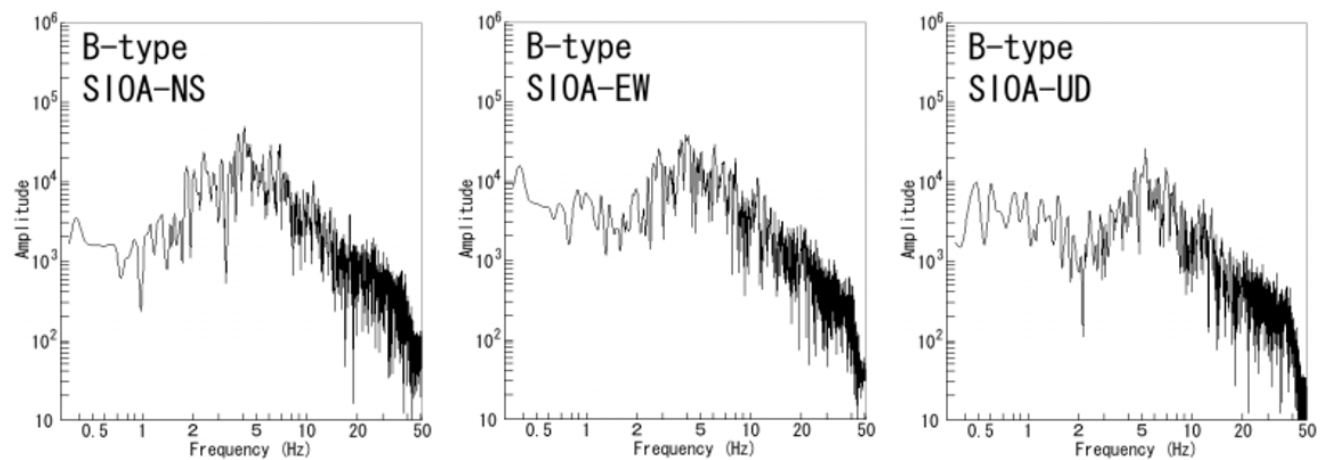

(b) B-type earthquake at 11:03:35 on Nov.27,1998.
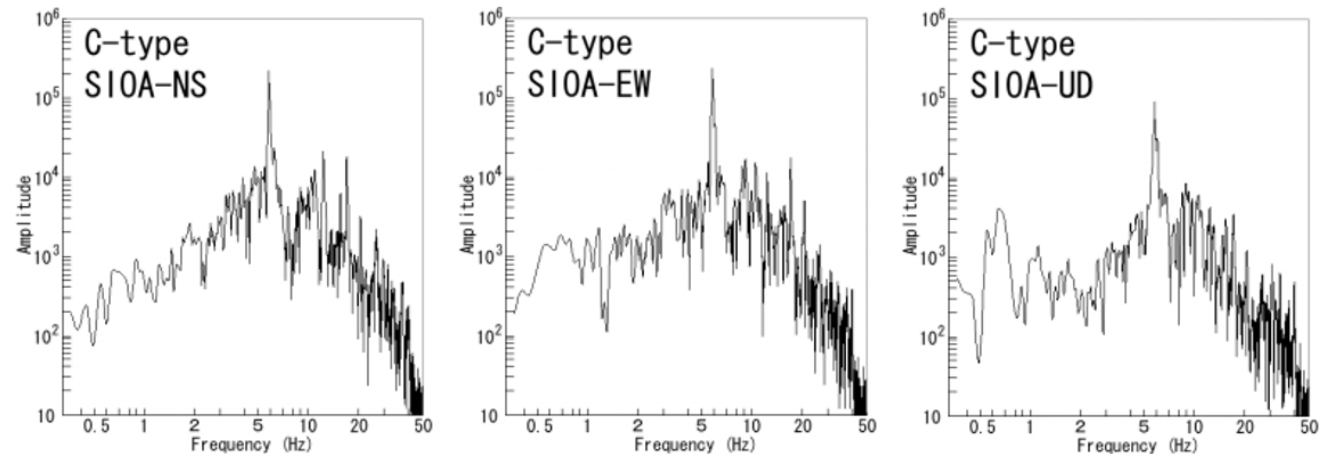

(c) C-type tremor at 05:56:34 on Feb.10,1999.
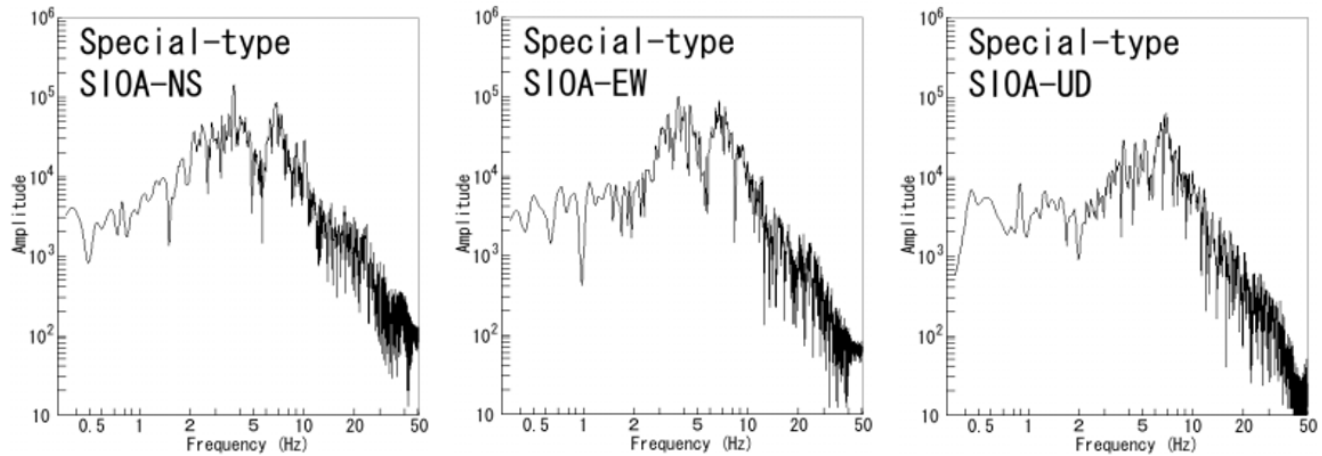

(d) Special-type earthquake at 15:46:29 on May 22,1998.

Fig. 5. Velocity spectra of the four types of seismic events (Seismic station is SIOA).

of the ascent of seismic activity. Meanwhile, it is notable that the numbers of B- and C-type and that of Special-type earthquakes are complementary to a considerable extent.

Figures 4 and 5 show examples of typical waveforms of four types of seismic events observed at SIOA and their ve- locity spectra, respectively. The time window of the spectrum analysis by FFT is 20.48 seconds from the onset of each waveform.

(a) A-type earthquakes have a clear and impulsive $P$ phase and $S$ phase. $S$ - $P$ time is mostly shorter than 1 second 


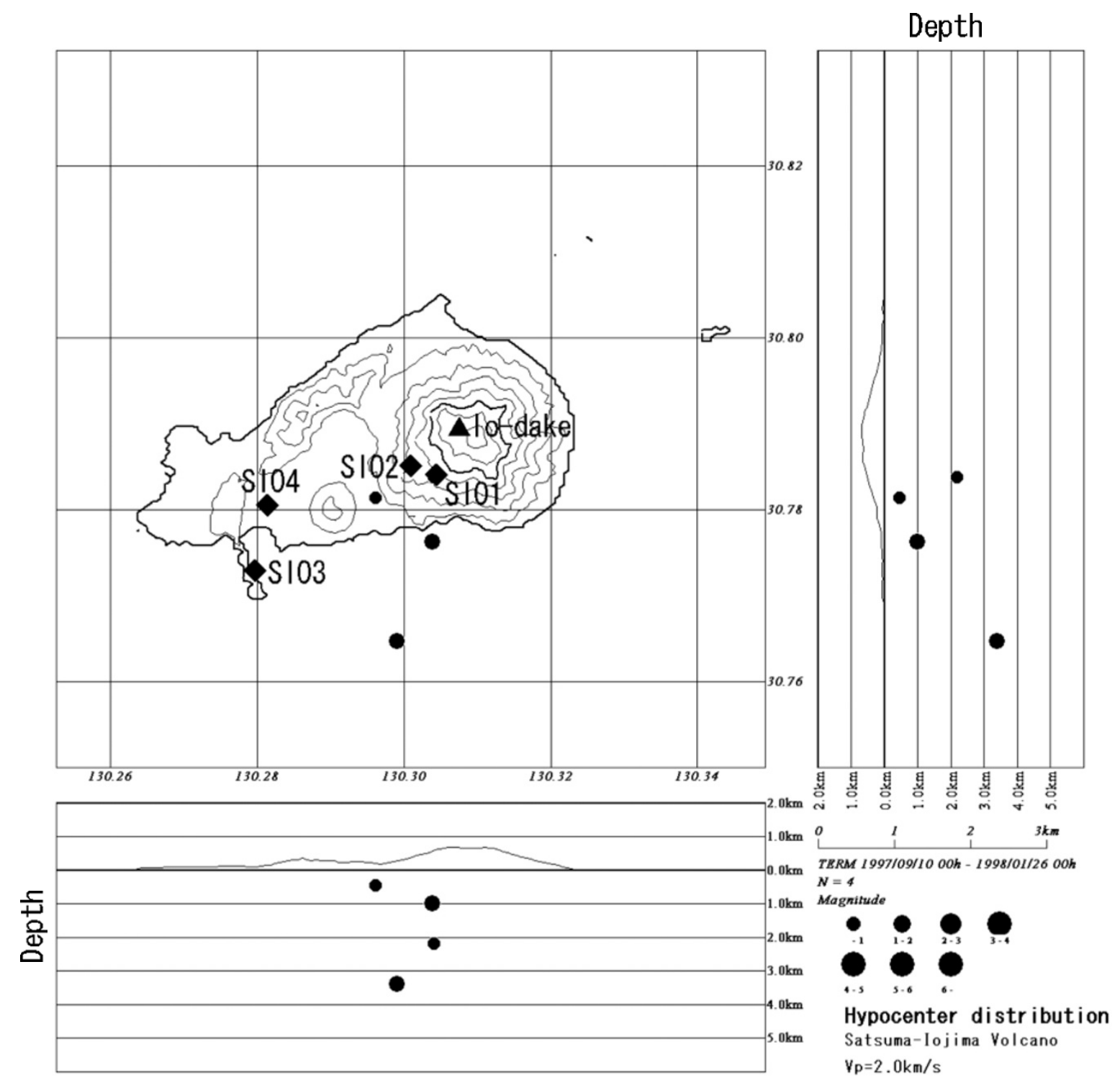

(a) Sep.10, 1997-Jan.25, 1998.

Fig. 6. Hypocenter distribution of A-type earthquakes ( $\bullet$ : Seismic stations).

in this observation period. Relatively high-frequency components $(5-20 \mathrm{~Hz})$ are dominant. Iguchi (1994) interpreted the source mechanisms of A-type earthquakes at Sakurajima volcano as the shear fracture of the rocks around the conduit. It is inferred that A-type earthquakes at Satsuma-Iojima are generated by the same mechanisms as on Sakurajima.

(b) B-type earthquakes do not have a distinct $P$ phase and $S$ phase. Relatively low-frequency components $(4-7 \mathrm{~Hz})$ are dominant and the most intense peak sits at about $4 \mathrm{~Hz}$, while relatively high-frequency components $(>10 \mathrm{~Hz})$ are weak. We consider that these characteristics are similar to those of the BH-type earthquakes at Sakurajima volcano (Ishihara and Iguchi, 1989). Iguchi et al. (1999) interpreted the source mechanisms of these B-type earthquakes at Satsuma-Iojima as an expansion of a gas pocket in the conduit filled with fluid based on an analogy with B-type earthquakes at Sakurajima. (c) C-type tremors have a waveform of a single-period oscillation lasting longer than 10 seconds, and its spectra have a sharp peak at about $6 \mathrm{~Hz}$. This type are further divided into two sub-types: Type- 1 has the long coda phase attenuating smoothly and slowly like the T-type earthquake at Asama volcano (Hamada et al., 1976), while Type-2 has the coda phase attenuating gradually repeating increase and decrease in amplitude like the C-type tremor at Sakurajima volcano (Nagamune, 1975; Kamo et al., 1977). Figure 4(c) shows an example of Type- 1 .

(d) Special-type earthquakes have a characteristic long phase called the "Emergent phase" (Ohminato and Ereditato, 1997), which precedes the appearance of the largest phase which we call the "Main phase" by 5-8 seconds and consists of weak seismic waves increasing gradually in amplitude. This earthquake's spectra have two relatively distinct peaks at about $4 \mathrm{~Hz}$ and $7 \mathrm{~Hz}$. 


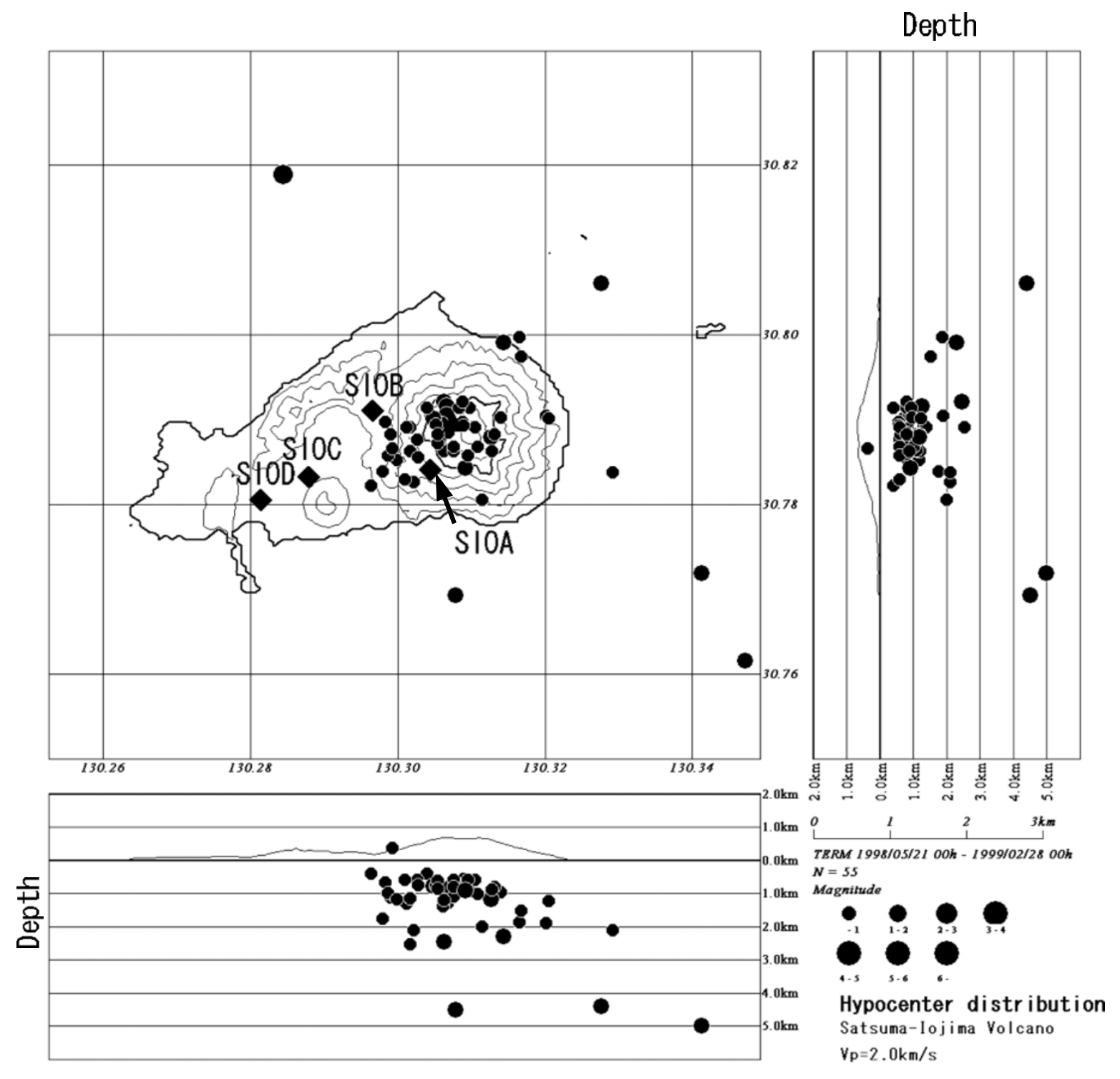

(b) May 21, 1998-Feb. 271999.

Fig. 6. (continued).

While many seismic events have been observed in the observation period, ones accompanied by an air-shock (infrasound) larger than the detection ability of the infrasonic microphone (about $0.02 \mathrm{~Pa}$ ) have not been observed as yet. It is judged that no explosive eruption occurred in this period, though weak emissions of volcanic ash from the summit crater were often observed.

\subsection{Hypocenter distribution of A-type earthquakes}

Figure 6(a) shows the hypocenter distribution of A-type earthquakes $(M \leqq 1.4)$ around Satsuma-Iojima from September 10, 1997 to January 25, 1998, i.e., the first period of our observation using the four seismographs. We adopted the half-infinity structure model assuming the $P$ wave velocity to be $2.0 \mathrm{~km} / \mathrm{s}$ for calculating the hypocenters. The number of A-type earthquakes was small in this period and we could determine only two hypocenters within the volcanic island and two in the southern sea area.
Figure 6(b) shows the hypocenter distribution of A-type earthquakes $(M \leqq 2.2)$ around the island from May 21, 1998 to February 27, 1999, i.e., the second period of our observation using four seismographs. The number of Atype earthquakes was relatively large in this period reflecting lively seismic activity at the volcano, and we could determine 55 of their hypocenters using a different seismic network from that used for the first observation period. Most of them were determined within $2 \mathrm{~km}$ from Io-dake in horizontal distance and within $3 \mathrm{~km}$ in depth.

Thus, we can conclude that the hypocenters of A-type earthquakes at Satsuma-Iojima volcano in these observation periods mostly existed in a shallow area within the volcanic island.

\subsection{Analysis on Special-type earthquakes}

Many "Special-type earthquakes" which have the "Emergent phase" were observed accompanying the recent ascent 

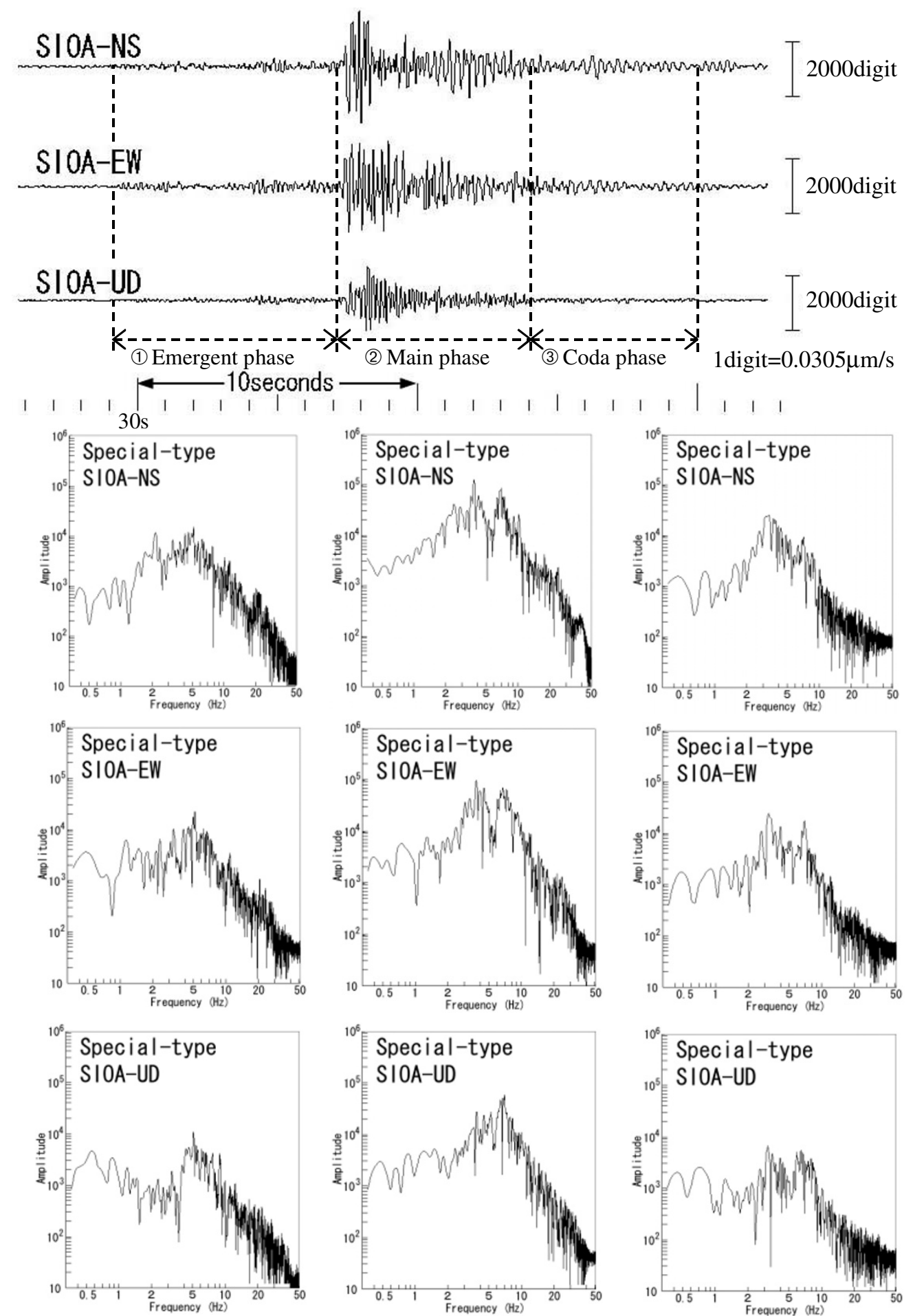

(1) Emergent phase

(2) Main phase

(3) Coda phase

Fig. 7. Velocity spectra of each phase of a Special-type earthquake (Seismic station is SIOA).

of seismic activity at Satsuma-Iojima volcano. Ohminato and Ereditato (1997) first reported the existence of the long "Emergent phase," and presumed the epicenters of Specialtype earthquakes $(M \sim 0)$ to be around the summit crater from the distribution of amplitudes detected by seismographs installed around the summit crater.

Special-type earthquakes have two relatively distinct peaks at about $4 \mathrm{~Hz}$ and $7 \mathrm{~Hz}$ (Fig. 5). The peak frequency in two horizontal components is different from that of the vertical component, i.e., the former sits at about $7 \mathrm{~Hz}$ while the latter sits at about $4 \mathrm{~Hz}$. The difference seems to be caused by the response property of the observation point. The peak at about $4 \mathrm{~Hz}$ is common to a B-type earthquake, but the sudden fall at about $5.5 \mathrm{~Hz}$ and another distinct peak at about $7 \mathrm{~Hz}$ are characteristics that are not found in the spectra of either A-type earthquakes or B-type earthquakes. On the 

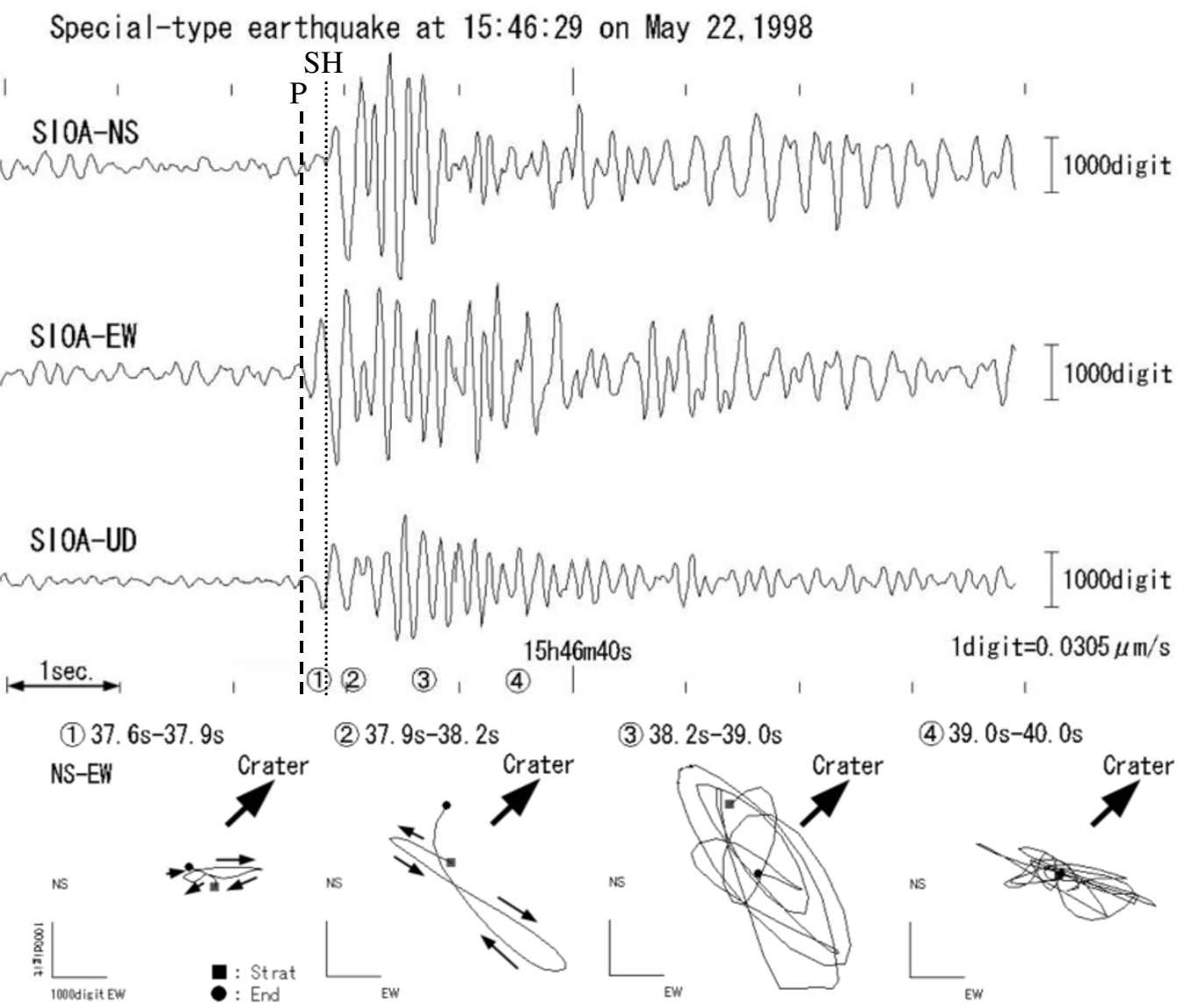

UD-EW
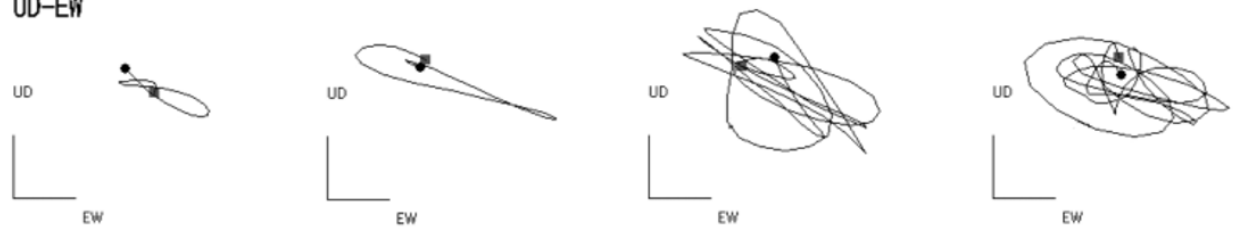

UD-NS
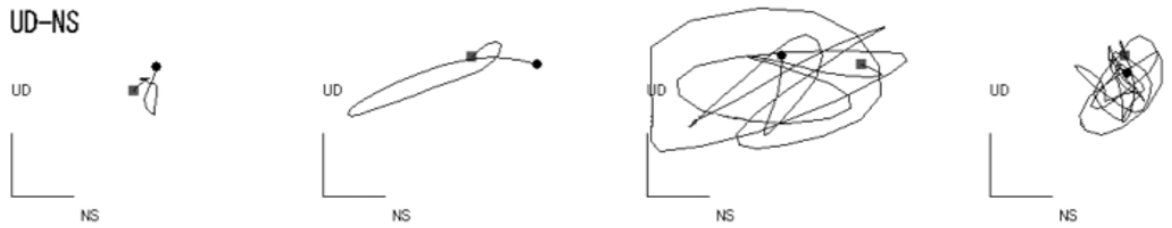

(a) Particle motion diagrams of the Main phase of a Special-type earthquake (Seismic station is SIOA).

Fig. 8. Particle motion diagrams of a Special-type earthquake.

other hand, a sudden decrease at relatively high-frequency components $(>10 \mathrm{~Hz})$ is similar to B-type earthquakes. This fact and the above-mentioned $4 \mathrm{~Hz}$ peak which is common to B-type earthquakes suggest that an expansion of a gas pocket in the conduit filled with fluid, which are considered to be the source mechanisms of B-type earthquakes (Iguchi et al., 1999), at least partially participates in the occurrence of Special-type earthquakes.

We will conduct further detailed spectrum analysis of the waveform of the Special-type earthquake dividing it into three phases: (1) Emergent phase, (2) Main phase, and (3) Coda phase. Figure 7 shows the velocity spectra of the three phases of the Special-type earthquake. (1) Emergent phase has the most intense peak at about $5 \mathrm{~Hz}$. (2) Main phase has two distinct peaks at about $4 \mathrm{~Hz}$ and $7 \mathrm{~Hz}$ as the abovementioned spectra of the whole waveform. (3) Coda phase has the most intense peak at about $3 \mathrm{~Hz}$. It is notable that the peak frequency of the Emergent phase and that of the Main phase apparently differ.

Next we show the results of particle motion analyses of 

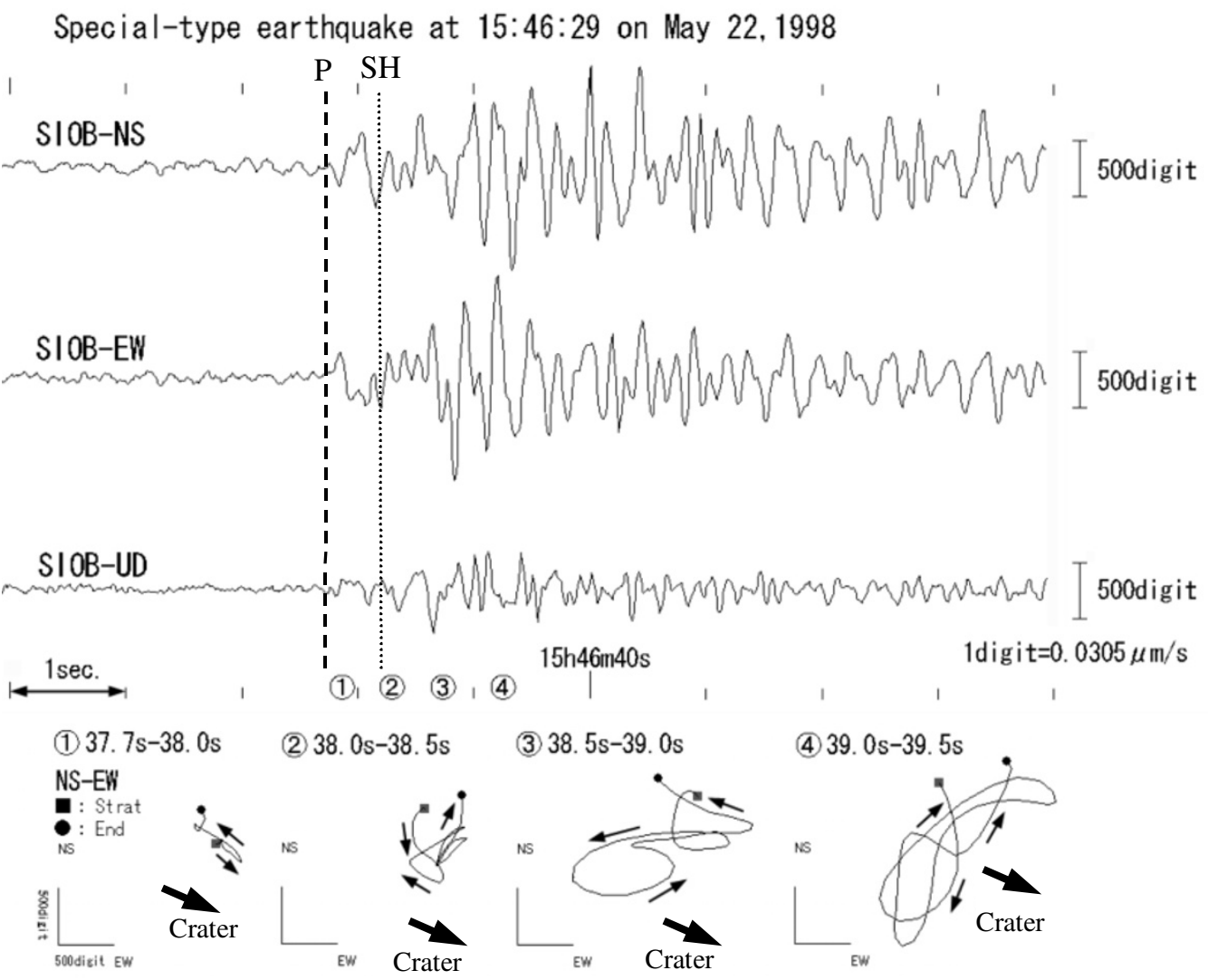

UD-EW
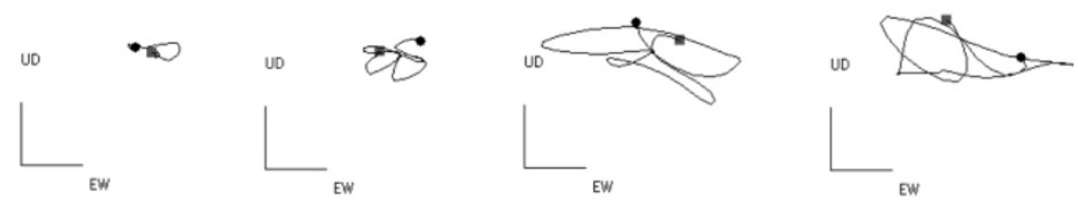

UD-NS
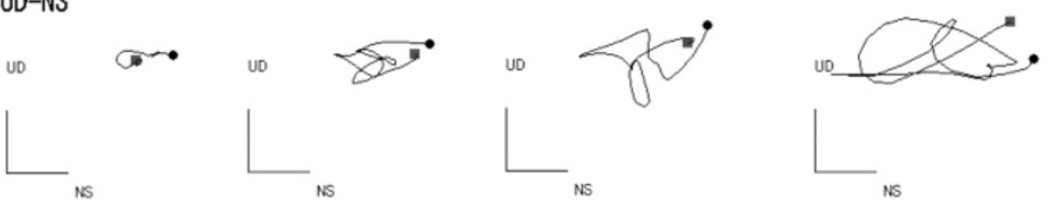

(b) Particle motion diagrams of the Main phase of a Special-type earthquake (Seismic station is SIOB).

Fig. 8. (continued).

the Special-type earthquake. We assume that the hypocenter of this earthquake exists in a shallow area below the summit crater according to Ohminato and Ereditato (1997).

Figure 8(a) shows the particle motion diagrams of the Main phase of the Special-type earthquake observed at SIOA ( $0.7 \mathrm{~km} \mathrm{SW}$ from the summit crater). Io-dake summit crater sits in the direction of $\mathrm{N} 45^{\circ} \mathrm{E}$ from SIOA. We show the particle motion diagrams from $15 \mathrm{~h} 46 \mathrm{~m} 37.6 \mathrm{~s}$, when a relatively distinct phase is seen first in the EW component. In the NS-EW diagram of the analysis section (1), the particle motion begins with the initial motion of "push" from the direction of the summit crater where the hypocenter is con- sidered to exist. Succeeding oscillation also nearly points in the direction of the radial component. Consequently, we consider that the seismic wave in this section is made up of $P$ waves. Besides, the hypocenter of this event can be presumed to be at a shallow depth below the summit crater, because the amplitude of the $P$ wave in the vertical component is much smaller than those of horizontal components at the onset. Next, the particle motions in the NS-EW diagrams of (2) and (3) point in the direction of the transverse component. Accordingly, they are considered to consist of $S H$ waves. The $S$ - $P$ time (about 0.3 second) is also in harmony with the distance between SIOA and a hypocenter assumed 

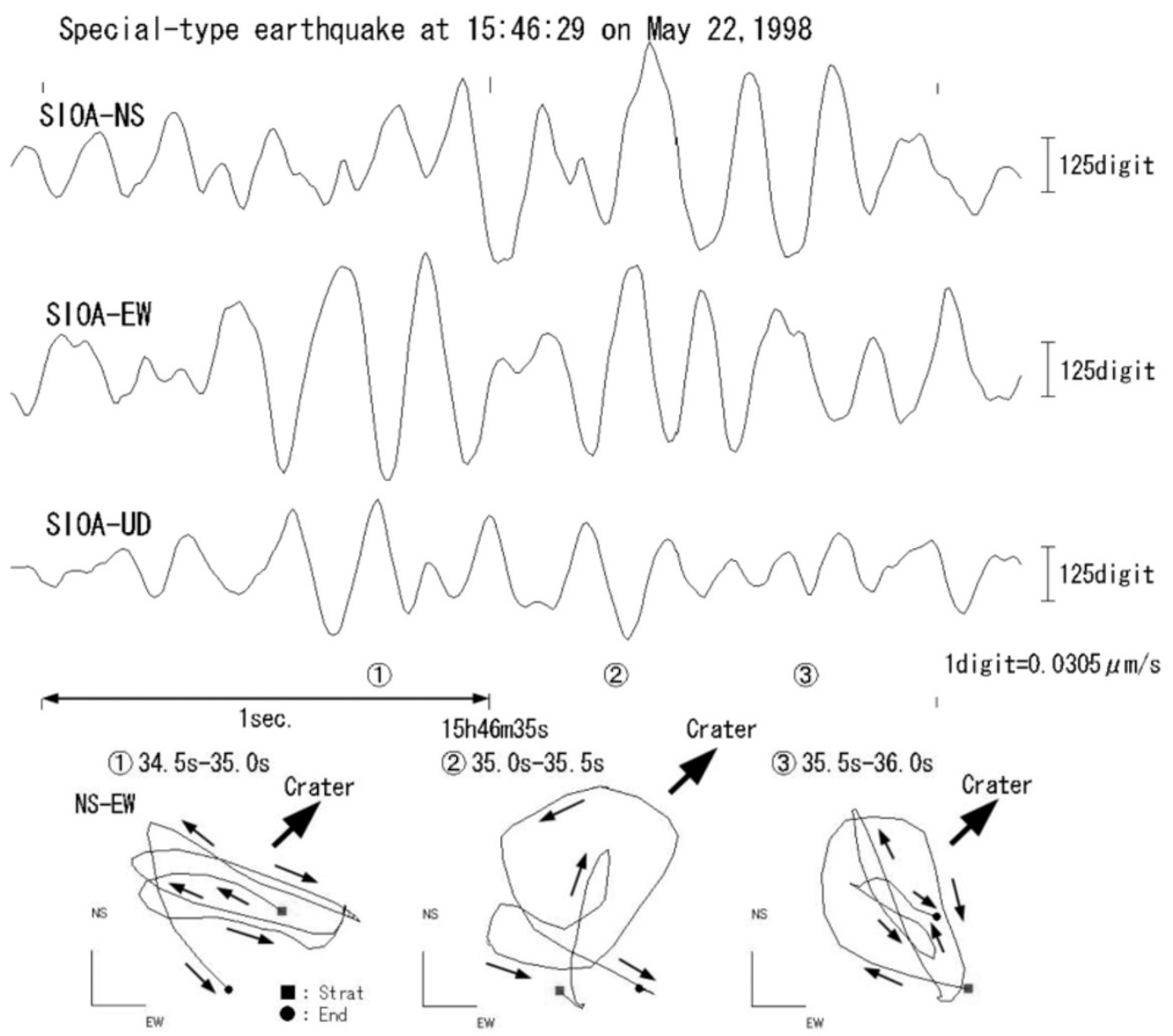

(2)

(3)

1digit $=0.0305 \mu \mathrm{m} / \mathrm{s}$

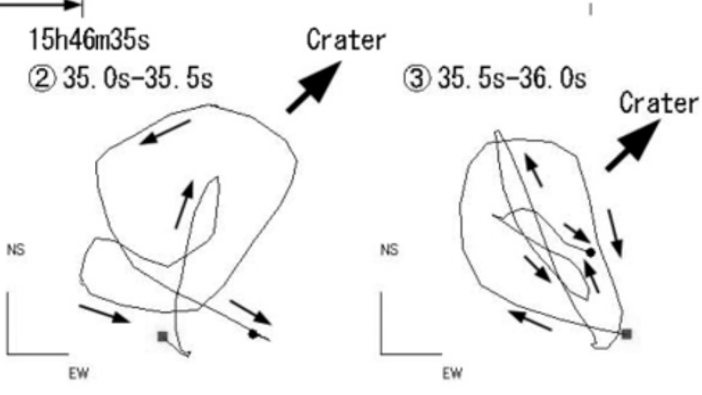

UD-EW
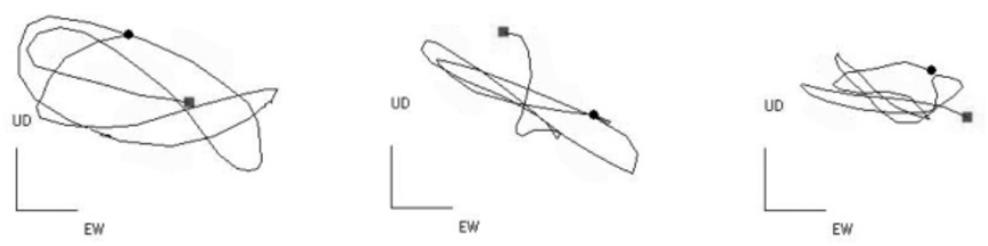

UD-NS
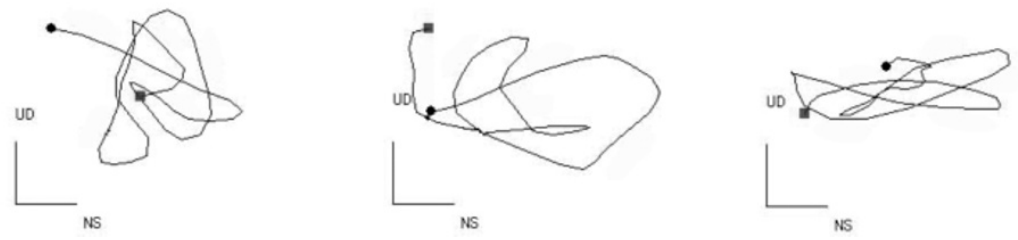

(c) Particle motion diagrams around the maximum amplitude of the Emergent phase of a Special-type earthquake (Seismic station is SIOA).

Fig. 8. (continued).

to be in a shallow area below the summit crater.

We conducted the same analysis using the waveform of the Special-type earthquake observed at SIOB $(1.3 \mathrm{~km}$ WNW from the summit crater). Figure 8(b) shows the particle motion diagrams of the Main phase of the earthquake observed at SIOB. Io-dake summit crater sits in the direction of $\mathrm{S}^{\circ} \mathrm{E}$ from SIOB. The particle motion in the NS-EW diagram of analysis section (1) almost points in the direction of the radial component. Consequently, the seismic wave in this section is considered to be a $P$ wave. Note that it apparently begins with the initial motion of "pull" toward the direction of the summit crater in contrast to the case of SIOA. After that, a transversal motion is seen in NS-EW diagrams of (2) and apparent transverse components are dominant in NS-EW diagrams of (4). Therefore, they are considered to consist of $S H$ waves or Love waves. 
The observational facts that the polarity of the $P$ onset at SIOA and SIOB differ from each other and that the distinct $S H$ waves exist, are not satisfactorily explained by an expansion of a gas pocket in the conduit filled with fluid, which was suggested above by the spectrum analysis. These facts will be explained more reasonably by the participation of a faulting source excited by the release of shear strain like tectonic earthquakes and volcanic A-type earthquakes.

Next we conducted the particle motion analysis of the Emergent phase, which is peculiar to Special-type earthquakes. The first motion of the phase is quite unclear and is not suitable for analysis, so we will analyze the section around the maximum point of the phase. Figure 8(c) shows the particle motion diagrams around the maximum point of the Emergent phase of the Special-type earthquake at SIOA. Transverse components are generally dominant in NS-EW diagrams, especially in (1) and (3). Besides, the vertical component is generally smaller than the horizontal component in UD-EW and UD-NS diagrams. Consequently, we consider that the Emergent phase mainly consists of $S H$ waves or Love waves.

\section{Discussions}

We put the above results of the analyses on the waveform of the Special-type earthquake together. The Specialtype earthquake begins with the Emergent phase, which has an unclear first motion and is rich in its $5 \mathrm{~Hz}$ component and is considered to mainly consist of $S H$ waves or Love waves. Then the Main phase appears 5-8 seconds after the appearance of the Emergent phase. It has clear $P$ waves ("push" at SIOA and "pull" at SIOB) and $S H$ waves, is rich in $4 \mathrm{~Hz}$ and $7 \mathrm{~Hz}$ components, and is lacking in relatively high-frequency components $(>10 \mathrm{~Hz})$ unlike A-type earthquakes. Finally, the Coda phase emerges, which is rich in $3 \mathrm{~Hz}$ component, and then the waveform of the earthquake ceases.

Though some uncertainty might exist in presuming the source mechanisms of Special-type earthquakes from our results of analyses so far, we propose a model for the source mechanisms of Special-type earthquakes as follows.

The relatively low-frequency $4 \mathrm{~Hz}$ peak and the lack of the relatively high-frequency components $(>10 \mathrm{~Hz})$ of the Main phase suggest that an expansion of a gas pocket in the conduit filled with fluid at least partially participates in the generation of the Main phase. However, the difference in the polarity of the $P$ onset at SIOA and SIOB and the existence of distinct $S H$ waves are not satisfactorily explained by a volumetric expansion model. It is more natural to consider that they are generated by the participation of a simultaneous faulting source. On the other hand, the lack of relatively high-frequency components does not agree with a faulting source within normal brittle rocks. Taking these constraints into consideration, we hypothesize a relatively slow and small-scale shear fracture within the rhyolitic magma, which is highly viscous but not completely solid, as a satisfying model for the source mechanisms of the Main phase.

Meanwhile, we hypothesize that the Emergent phase, which precedes the Main phase and has a waveform similar to normal volcanic tremors, corresponds to a process of a somewhat continuous bubbling of gas within the rhy- olitic magma. Though simple bubbling cannot generate $S H$ waves or Love waves that characterize the Emergent phase, an ellipsoidal expansion $\left(M_{x x} \neq M_{y y}\right)$ can excite these types of waves. Then the gas separates from the liquid phase of the rhyolitic magma and heightens its pressure gradually, and disarranges the balance of stress distribution within the rhyolitic magma. Finally, it causes a relatively slow and smallscale shear fracture in the highly viscous rhyolitic magma to produce the Main phase 5-8 seconds after the start of gas bubbling.

These hypotheses can explain the difference in the polarity of the $P$ onset at SIOA and SIOB and the existence of distinct $S H$ waves of the Main phase. The existence of a $7 \mathrm{~Hz}$ peak and the lack of relatively high-frequency components can also be explained by the relatively slow speed shear fracture in the rhyolitic magma, which is highly viscous but not completely solid. On the other hand, if the high-pressure gas breaks into the newly formed fault plane, the volumetric expansion of the gas is realized and a low-frequency $4 \mathrm{~Hz}$ peak, which is similar to B-type earthquakes, can be generated simultaneously. Moreover, the dispersion of the duration of the Emergent phase (5-8 seconds) can be considered to result from the dispersion of the time from the start of gas bubbling to the occurrence of the shear fracture. Thus, our "bubbling and shear fracture model" can explain all the characteristics of Special-type earthquakes synthetically.

However, our model is still a preliminary one. Especially, detailed and careful investigation is needed to confirm whether or not the shear fracture in the rhyolitic magma is realized by the gas bubbling. More detailed observations and excellent analyses are expected for the establishment of a certain source mechanism model of Special-type earthquakes.

\section{Conclusions}

FDMO has continued a seismic observation at SatsumaIojima volcano since September 1997.

The daily number of seismic events at this volcano ranged from several to 130 . We classified these volcanic earthquakes into four types, i.e., A-type earthquake, B-type earthquake, C-type tremor, and Special-type earthquake. The increase in number was controlled by the seismicity of Special-type earthquakes.

The hypocenters of A-type earthquakes in this observation period mostly existed in a shallow area within the volcanic island.

The Special-type earthquakes have an Emergent phase, which precedes the appearance of the Main phase by 5 8 seconds and consists of weak seismic waves increasing gradually. The Emergent phase has a spectrum structure in which the $5 \mathrm{~Hz}$ component exceeds and is considered to mainly consist of $S H$ waves or Love waves. The Main phase has a spectrum structure in which $4 \mathrm{~Hz}$ and $7 \mathrm{~Hz}$ components exceed and relatively high-frequency components $(>10 \mathrm{~Hz})$ lack, while it has clear $P$ waves ("push" and "pull") and $S H$ waves similar to A-type earthquakes. We may conclude that at first an ellipsoidal bubbling of gas within the rhyolitic magma generates the Emergent phase, and secondly a slow and small-scale shear fracture occurs within the highly 
viscous rhyolitic magma to produce the Main phase 5-8 seconds after the initial gas bubbling.

Acknowledgments. We wish to thank Mishima Elementary and Junior High School, which kindly let us install the observation machines at their site. We also wish to thank Mishima Village Office Iojima Branch, and Iojima Police Box, which obligingly supported our observation. We are exceedingly grateful to Mr. Hiroshi Shinohara of Geological Survey of Japan who gave us the opportunity of writing this manuscript. We are also extremely grateful to Assistant Professor Masato Iguchi of Sakurajima Volcano Research Center of Kyoto University for giving us so much information on the volcano and precious advice on our manuscript. We acknowledge Professor Kisei Kinoshita of Kagoshima University who offered us useful information about the activity of the volcano. We wish to express our gratitude to Mr. Makoto Nishiwaki of Japan Meteorological Agency for his kind advice and continuous encouragement. Our thanks are also given to Ms. Yumi Umeno for assistance in the analyses and preparing the figures. This paper was significantly improved by accurate reviews of two anonymous reviewers.

\section{References}

Fukuoka District Meteorological Observatory, Report of Kyusyu District Mobile Volcano Observation at Satsuma Iojima volcano, 6, 21 pp., 1986 (in Japanese).

Fukuoka District Meteorological Observatory, Report of Kyusyu District Mobile Volcano Observation at Tsurumidake and Satsuma Iojima volcano, 13, pp. 41-59, 1993 (in Japanese).

Geological Survey of Japan, Recent volcanic activity at the summit of Iwodake, Satsuma-Iwojima, Report of Coordinating Committee for Prediction of Volcanic Eruption, 67, 79-82, 1997 (in Japanese).
Hamada, N., H. Jingu, and K. Ikumoto, On the Volcanic Earthquakes with Slowly Decaying Coda Wave, Bull. Volconol. Soc. Jpn., 21, 167-183, 1976 (in Japanese with English abstract).

Iguchi, M., Vertical expansion source model for the mechanisms of earthquakes originated in the magma conduct of an andesitic volcano: Sakurajima, Japan, Bull. Volcanol. Soc. Jpn., 39, 49-67, 1994.

Iguchi, M., K. Ishihara, T. Takayama, T. Tamekuri, H. Shinohara, and E. Saito, Volcanic activity at Satsuma-Iwojima during 1995-1998, Annuals of Disas. Prev. Res. Inst., Kyoto Univ., 42 B-1, 1-10, 1999 (in Japanese with English abstract).

Ishihara, K. and M. Iguchi, The Relationship between Micro-earthquake Swarms and Volcanic Activity at Sakurajima Volcano, Annuals of Disas. Prev. Res. Inst., Kyoto Univ., 32 B-1, 1-11, 1989 (in Japanese with English abstract).

Japan Meteorological Agency, Satsuma-Iojima, in National Catalogue of the Active Volcanoes in Japan (second edition), pp. 395-399, 1991 (in Japanese).

Kamo, K., T. Furusawa, and J. Akamatsu, Some Natures of Volcanic Microtremors at the Sakura-jima Volcano, Bull. Volconol. Soc. Jpn., 22, 41-58, 1977 (in Japanese with English abstract).

Kobayashi, T., Satsuma-Iojima, in Volcanoes in Japan, pp. 212-214, Maruzen, Tokyo, 1989 (in Japanese).

Nagamune, T., Volcanic tremors of C Type observed at Sakurajima, Bull. Volconol. Soc. Jpn., 20, 157-168, 1975 (in Japanese with English abstract).

Ohminato, T. and D. Ereditato, Broadband seismic observations at Satsuma-Iwojima volcano, Japan, Geophys. Res. Lett., 24, 2845-2848, 1997.

N. Uchida (e-mail: n-uchida@met.kishou.go.jp) and T. Sakai (e-mail: tsakai@mri-jma.go.jp) 